\title{
KARAKTERISTIK ANODA BATERAI LITHIUM-ION YANG DIBUAT DENGAN METODE SPRAYING BERBASIS BINDER CMC
}

\author{
IDA FARIDA ANTIKA*, SAHRUL HIDAYAT \\ Departemen Fisika Fakultas MIPA Universitas Padjadjaran, \\ Jl. Raya Bandung-Sumedang Km 21,Jatinangor 45363 \\ *email : idafaridaantika@gmail.com
}

\begin{abstract}
Abstrak. Baterai Lithium-ion merupakan salah satu jenis baterai sekunder yang umum digunakan pada perangkat portable karena keunggulan yang dimilikinya, yaitu siklus hidup yang panjang dan densitas energi yang tinggi. Performa baterai Li-ion ditentukan oleh kualitas elektrodanya. Kualitas elektroda dapat ditingkatkan dengan penambahan binder yang berfungsi untuk mempertahankan struktur fisik elektroda. Salah satu jenis binder yang dapat digunakan adalah Carboxymethyl Cellulose (CMC). CMC memiliki karakteristik yang baik sebagai perekat namun memiliki sifat listrik yang buruk karena isolator. Untuk mengatasi hal tersebut, elektroda dibuat dalam bentuk komposit dengan menambahkan bahan konduktif. Pada penelitian ini telah dibuat anoda baterai Li-ion berbasis binder CMC dengan variasi bahan konduktif berupa Acetylene black (AB) dan Karbon (C), dan variasi ketebalan film yang didapatkan dari banyaknya larutan anoda yang terdeposisi pada substrat. Berdasarkan penelitian yang telah dilakukan, nilai konduktivitas terbesar yaitu $6,781 \times 10^{3} \mathrm{~S} / \mathrm{m}$ dimiliki oleh film anoda komposit Grafit/AB/CMC dengan ketebalan film 0,200 mm. Sedangkan kapasitas terbesar dimiliki oleh film anoda komposit Grafit/AB/CMC ketebalan 0,422 mm. Namun yang memiliki stabilitas terbaik adalah film anoda komposit Grafit/C/CMC ketebalan 0,369 mm yang dapat mencapai hingga 1525 siklus pengujian cyclic voltammetry.
\end{abstract}

Kata kunci: anoda baterai, spraying, acetylene black, karbon konduktif, CMC

\begin{abstract}
Lithium-ion battery is a secondary battery that commonly used on portable devices because of it's high energy density and life cycles. Battery performance depends on the quality of electrodes. Electrodes quality can be improved by adding a binder. The function of binder is to maintain the structure of electrodes. The type of binder that can be used is Carboxymethyl Cellulose (CMC). CMC has a good characteristic for being binder but has poor electrical properties due to insulators. Based on this case, electrodes are made in composite form by adding conductive materials. In this study, a Li-ion battery anode that based on CMC binders has been made by giving a variety of conductive materials such as Acetylene Black ( $\mathrm{AB}$ ) and Carbon (C), and a variety of anode film thickness that obtained from the amount of anode solution deposited on the substrate. In this study, the highest conductivity is $6.781277 \times 10^{3} \mathrm{~S} / \mathrm{m}$ that owned by the Graphite/AB/CMC film with 0,2 mm film thickness. And the largest capacity is owned by Graphite/AB/CMC film with $0,422 \mathrm{~mm}$ film thickness. But, the anode film that has the best stability is Graphite/C/CMC film $0,369 \mathrm{~mm}$ film thickness which can do up to 1525 cycles in cyclic voltammetry test.
\end{abstract}

Keywords: battery anode, spraying, acetylene black, conductive carbon, CMC

\section{Pendahuluan}

Baterai Lithium-ion merupakan salah satu jenis baterai sekunder (rechargeable) yang umum digunakan terutama pada berbagai peralatan elektronik portable. 
Baterai ini memiliki beberapa kelebihan yang membuatnya unggul dibandingkan jenis baterai lainnya, diantaranya adalah memiliki energi spesifik, densitas, dan efisiensi energi yang tinggi. Serta memiliki kemampuan pengisian yang cepat dan masa hidup yang relatif panjang [1].

Meninjau pengaplikasian baterai Li-ion yang begitu luas, maka hal ini berpengaruh terhadap meningkatnya kebutuhan akan baterai yang memiliki performa yang baik. Salah satu faktor yang dapat mempengaruhi performa baterai adalah kualitas elektrodanya. Contohnya adalah terjadinya pengelupasan elektroda yang akan menjadi penyebab utama kerusakan baterai. Oleh karena itu, solusi yang dapat diberikan untuk mencegah terjadinya hal tersebut adalah dengan menemukan material penyusun elektroda yang optimal.

Bahan yang umum digunakan sebagai penyusun anoda baterai Li-ion adalah grafit. Dibandingkan dengan bahan anoda lainnya seperti $\mathrm{Li}_{4} \mathrm{Ti}_{5} \mathrm{O}_{12}$, grafit lebih unggul karena sifatnya yang konduktif, memiliki kapasitas yang besar, dan ramah lingkungan [2]. Namun, masih banyak ditemui kasus kerusakan baterai yang diakibatkan oleh pengelupasan elektroda. Maka dibutuhkan bahan tambahan untuk mempertahankan struktur fisik elektroda. Bahan yang dapat ditambahkan adalah Binder.

Binder atau perekat adalah material yang digunakan untuk mengikat atau menyatukan material aktif penyusun elektroda. Binder berperan dalam menjaga kualitas fisik dari elektroda sehingga dapat meningkatkan masa hidup baterai. Salah satu alternatif binder yang dapat digunakan adalah CMC (Carboxy Methyl Cellulose) yang merupakan bahan turunan dari selulosa [3]. CMC merupakan perekat selulosa terbaik untuk anoda dengan bahan aktif grafit pada baterai Li-ion [4]. Namun CMC memiliki sifat listrik yang buruk karena termasuk kedalam jenis isolator. Akibatnya, konduktivitas anoda akan berkurang. Sehingga dibutuhkan tambahan berupa bahan konduktif untuk meningkatkan nilai konduktivitas. Jenis bahan koduktif yang dapat digunakan adalah karbon konduktif (C) dan acetylene black (AB).

Berdasarkan hal tersebut, maka dalam penelitian ini dibuat film anoda baterai Liion dalam bentuk komposit Grafit + bahan konduktif + CMC dengan memberikan variasi bahan konduktif dan variasi ketebalan film. Pemberian variasi ini diharapkan akan menghasilkan film anoda dengan nilai konduktivitas yang tinggi, serta nilai kapasitansi dan siklus hidup terbaik dari baterai Li-ion.

\section{Metode Penelitian}

Film anoda dibuat dari campuran serbuk grafit, $\mathrm{CMC}$, dan bahan konduktif yang dilarutkan dalam pelarut aquades. Pada penelitian ini diberikan dua jenis variasi yakni variasi bahan konduktif dan variasi ketebalan film. Bahan konduktif yang digunakan adalah Karbon (C) dan Acetylene Black (AB). Variasi ketebalan didapatkan dari banyaknya larutan yang di deposisikan pada substrat, yaitu $1 \mathrm{~g} / 10 \mathrm{ml}$ dan $2 \mathrm{~g} / 10 \mathrm{ml}$, dimana tiap satu gram terdiri dari $90 \%$ grafit, $2 \% \mathrm{CMC}$, dan $8 \%$ bahan konduktif. Variasi pembuatan sampel ditunjukkan pada Tabel 1. 
Tabel 1. Variasi pembuatan sampel

\begin{tabular}{|c|c|c|}
\hline $\begin{array}{l}\text { Sampel } \\
\text { larutan }\end{array}$ & Massa bahan aktif & Volume pelarut $(\mathrm{ml})$ \\
\hline 1 & $\begin{array}{ll}\text { 1 } & \text { gram, terdiri dari: } \\
\text { - } & \text { Grafit } 90 \% \\
- & \text { Karbon (C) 8\% } \\
- & \text { CMC 2\% }\end{array}$ & 10 \\
\hline 2 & $\begin{array}{ll}2 \text { gram, terdiri dari: } \\
- & \text { Grafit } 90 \% \\
- & \text { Karbon (C) } 8 \% \\
- & \text { CMC 2\% }\end{array}$ & 20 \\
\hline 3 & $\begin{array}{l}1 \text { gram, terdiri dari: } \\
\text { - } \text { Grafit } 90 \% \\
\text { - } \text { Acetylene Black (AB) } 8 \% \\
\text { - } \text { CMC } 2 \%\end{array}$ & 10 \\
\hline 4 & $\begin{array}{l}2 \text { gram, terdiri dari: } \\
\text { - } \text { Grafit } 90 \% \\
\text { - } \text { Acetylene Black (AB) } 8 \% \\
\text { - } \quad \text { CMC } 2 \%\end{array}$ & 20 \\
\hline
\end{tabular}

Pembuatan larutan diawali dengan melarutkan CMC dalam aquades kemudian diaduk menggunakan magnetic stirrer pada suhu $50^{\circ} \mathrm{C}$ selama 20 menit atau sampai CMC benar-benar larut. Selanjutnya ditambahkan serbuk grafit dan bahan konduktif, kemudian diaduk kembali selama 3 jam. Larutan yang telah di buat kemudian dideposisikan pada permukaan substrat $\mathrm{Cu}$ foil ukuran $5 \mathrm{~cm} \times 15 \mathrm{~cm}$ dengan teknik deposisi spraying. Satu resep larutan di deposisi pada satu sisi substrat $\mathrm{Cu}$ foil. Artinya, dibutuhkan dua resep larutan yang sama untuk dideposisikan pada satu lembar substrat $\mathrm{Cu}$ foil.

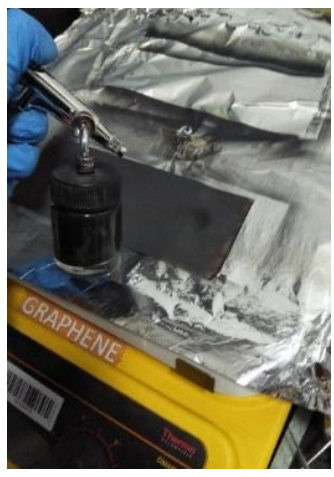

Gambar 1. Proses deposisi larutan dengan metode spraying

Kemudian dilakukan uji morfologi permukaan film anoda untuk mengetahui homogenitas film, persebaran material aktif, dan juga memungkinkan untuk mengetahui ukuran dan struktur dari partikel material penyusun film anoda. Pengujian dilakukan dengan menggunakan Scanning Electron Microscope (SEM) dengan perbesaran $2700 \times$.

Selanjutnya dilakukan pengujian konduktivitas untuk film anoda menggunakan four line probe yang terhubung dengan DC Current/Voltage source dan multimeter. Nilai arus pada DC Current/Voltage source divariasikan sebesar 0,5mA-5mA dengan kenaikan $0,5 \mathrm{~mA}$, lalu mencatat nilai tegangan yang terukur pada multimeter. Nilai konduktivitas dapat diketahui dengan mengolah data hasil pengukuran menggunakan persamaan (1). 


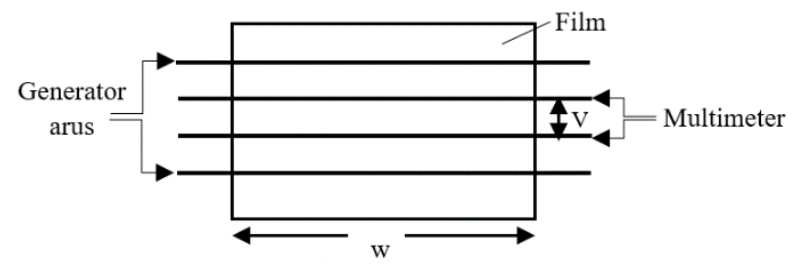

Gambar 2. Skema pengukuran konduktivitas

$$
\sigma=\frac{I}{V} \frac{d}{w t}
$$

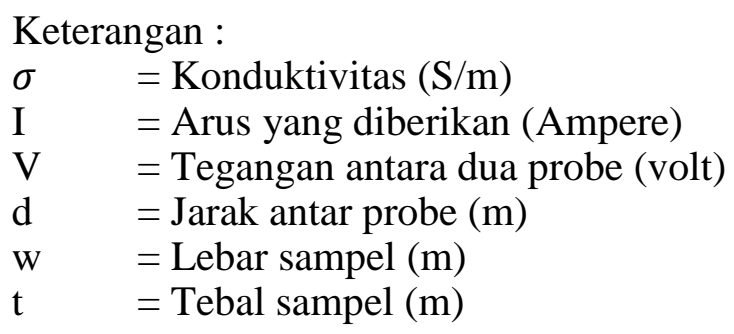

Tahap selanjutnya adalah melakukan uji cyclic voltammetry (CV) untuk mengetahui reaksi reduksi-oksidasi (redoks) dari sistem baterai. Sistem baterai pada pengujian ini terdiri dari sampel film anoda, katoda $\left(\mathrm{LiFePO}_{4}\right)$, dan elektrolit $\left(\mathrm{LiClO}_{4} 1 \mathrm{M}\right)$. Ukuran film anoda dan katoda adalah $1 \mathrm{~cm} \times 2,5 \mathrm{~cm}$, dimana bagian yang tercelup elektrolit adalah sebesar $1 \mathrm{~cm} \times 1,5 \mathrm{~cm}$. Pada pengujian ini, anoda berlaku sebagai elektroda lawan (counter electrode), dan katoda berlaku sebagai elektroda kerja (working electrode). Rentang tegangan diatur sebesar $-1,25 \mathrm{~V}$ sampai $1 \mathrm{~V}$, dan nilai scan rate divariasikan sebesar $25 \mathrm{mV} / \mathrm{s}, 50 \mathrm{mV} / \mathrm{s}, 75 \mathrm{mV} / \mathrm{s}$, $100 \mathrm{mV} / \mathrm{s}$, dan $125 \mathrm{mV} / \mathrm{s}$. Untuk mengetahui stabilitas siklus, dilakukan pengujian sebanyak 20 siklus pada scan rate $75 \mathrm{mV} / \mathrm{s}$. Melalui pengujian ini, dapat diketahui nilai daya, kapasitansi, serta dapat memperkirakan masa hidup dari sistem baterai Li-ion.

\section{Hasil dan Pembahasan}

Dari hasil pembuatan film anoda, diperoleh film dengan variasi ketebalan. Tabel 2 berikut memperlihatkan besar ketebalan film anoda yang terdeposisi pada substrat Cu foil.

Tabel 2. Ketebalan film anoda

\begin{tabular}{ccc}
\hline Sampel & Film & Ketebalan $(\mathbf{m m})$ \\
\hline 1 & Grafit/C/CMC & 0,177 \\
2 & & 0,369 \\
3 & Grafit/AB/CMC & 0,200 \\
4 & & 0,422 \\
\hline
\end{tabular}

Hasil deposisi film anoda menunjukkan bahwa film 2 dan 4 lebih tebal dibandingkan dengan film 1 dan 3. Karena volume larutan anoda yang terdeposisi pada film 2 dan 4 adalah $20 \mathrm{ml}$, artinya film ini akan dua kali lebih tebal dibandingkan dengan film 1 dan 3 . Hal ini diakibatkan oleh adanya penumpukan material pada substrat. 
Hasil uji morfologi menggunakan SEM dengan perbesaran 2700× ditunjukkan pada Gambar 3.

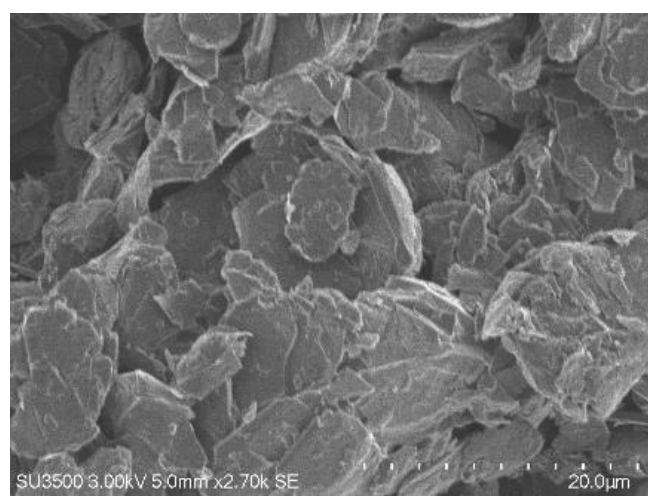

(a)

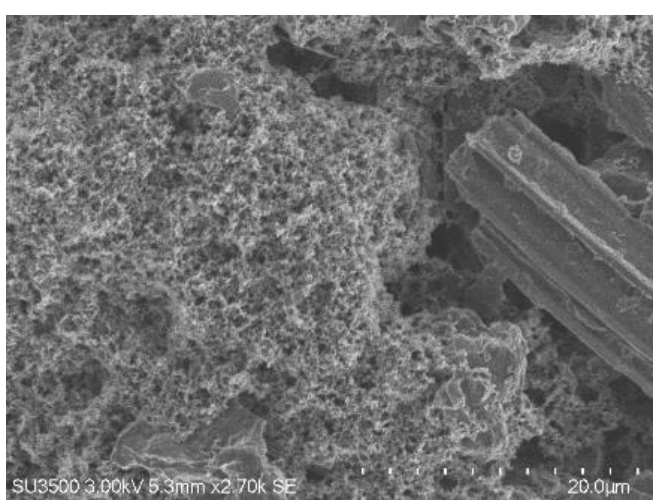

(b)

Gambar 3. Hasil SEM film anoda komposit (a) Graft/C/CMC, dan (b) Grafit/AB/CMC

Gambar 3 menunjukkan stuktur AB dan grafit yang dapat dibedakan dengan jelas. AB memiliki struktur berpori. Selain itu terlihat adanya celah yang cukup besar yang memisahkan material-material penyusun film ini. Dari hasil SEM, keberadaan CMC tidak dapat digambarkan karena $\mathrm{CMC}$ telah larut dalam aquades, namun keberadaannya dapat dketahui dari kemampuannya dalam merekatkan material penyusun anoda. Dapat dilihat bahwa CMC memiliki kemampuan yang lebih baik dalam merekatkan material Grafit/C dibandingkan Grafit/AB, terbukti dari rapatnya material-material penyusun film anoda komposit Grafit/C/CMC.

Berdasarkan pengujian konduktivitas, didapatkan hasil seperti yang tertera pada Tabel 3

Tabel 3. Nilai konduktivitas film anoda.

\begin{tabular}{|c|c|c|c|}
\hline \multirow{2}{*}{ Sampel } & \multicolumn{2}{|l|}{ Film } & \multirow{2}{*}{$\sigma \times 10^{3}(\mathrm{~S} / \mathrm{m})$} \\
\hline & Komposit & d (mm) & \\
\hline 1 & \multirow{2}{*}{ Grafit/C/CMC } & 0,177 & 3,652 \\
\hline 2 & & 0,369 & 1,888 \\
\hline 3 & \multirow{2}{*}{ Grafit/AB/CMC } & 0,200 & 6,781 \\
\hline 4 & & 0,422 & 4,527 \\
\hline
\end{tabular}

Keterangan:

$\mathrm{d}=$ Ketebalan film anoda $(\mathrm{mm})$

$\sigma=$ Konduktivitas listrik $(\mathrm{S} / \mathrm{m})$

Secara keseluruhan didapatkan bahwa nilai konduktivitas tertinggi adalah sebesar $6,781 \times 10^{3} \mathrm{~S} / \mathrm{m}$ yang dimiliki oleh sampel 3 . Hasil ini berkorelasi dengan hasil karakterisasi morfologi permukaan film anoda yang menunjukkan struktur $\mathrm{AB}$ yang berpori serta memiliki banyak celah. Pori ini digunakan sebagai jalur untuk mobilitas elektron sehingga mempermudah aliran muatan. Sebagai akibatnya, maka nilai konduktivitas akan tinggi. 
Untuk mengetahui nilai daya dan kapasitansi baterai, dilakukan pengujian Cyclic voltammetry dengan variasi scan rate. Hasil pengukuran ditunjukkan pada Gambar 4.



Gambar 4. Kurva Cyclic voltammetry sistem baterai Li-ion dengan variasi scan rate pada sampel film anoda Grafit/AB/CMC ketebalan 0,200 mm

Gambar 4 menampilkan hubungan antara tegangan yang diberikan dan respon arus yang dihasilkan. Terlihat bahwa scan rate akan mempengaruhi luasan kurva CV yang dihasilkan. Saat scan rate kecil, maka kenaikan tegangan juga cukup kecil. Akibatnya, respon arus yang dihasilkan juga kecil. Sehingga dihasilkan luas kurva yang relatif sempit. Besarnya luasan kurva ini identik dengan nilai daya yang dihasilkan.



(a)

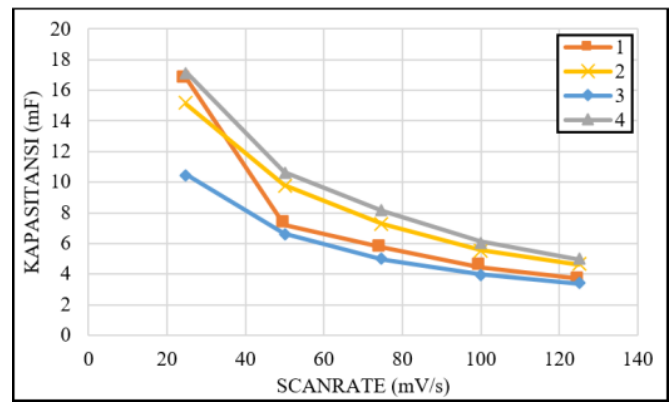

(b)

Gambar 5. Grafik hubungan (a) Daya terhadap scan rate, dan (b) Kapasitansi terhadap scan rate tiap sampel film anoda

Keterangan :

$1=$ Film anoda komposit Grafit/C/CMC ketebalan 0,177 mm

$2=$ Film anoda komposit Grafit/C/CMC ketebalan $0,369 \mathrm{~mm}$

$3=$ Film anoda komposit Grafit/AB/CMC ketebalan $0,200 \mathrm{~mm}$

$4=$ Film anoda komposit Grafit/AB/CMC ketebalan $0,422 \mathrm{~mm}$

Gambar 5 menunjukkan hubungan daya dan kapasitansi terhadap scan rate. Disini terbukti bahwa terdapat hubungan yang berbanding lurus antara nilai daya dan scan rate. Sedangkan nilai kapasitansi cenderung menurun seiring dengan kenaikan scan rate. Hal ini dikarenakan semakin besar scan rate, maka respon arus yang dihasilkan akan semakin besar pula. Hal ini memicu pergerakan ion lithium yang semakin cepat sehingga muatan belum sempat menempati pori elektroda. 
Akibatnya kapasitansi yang terukur cenderung kecil. Berdasarkan hasil ini didapatkan nilai rata-rata kapasitansi terbesar dimiliki oleh sistem baterai Li-ion dengan film anoda Grafit/AB/CMC ketebalan 0,422 mm yakni sebesar 9,4mF.

Dengan uji CV juga dapat diketahui stabilitas dan siklus hidup baterai. Dilakukan dengan pengujian sebanyak 20x siklus pada scan rate $75 \mathrm{mV} / \mathrm{s}$, didapatkan stabilitas film anoda yang ditinjau dari nilai kapasitansi terhadap siklus seperti yang ditunjukkan Gambar 6.

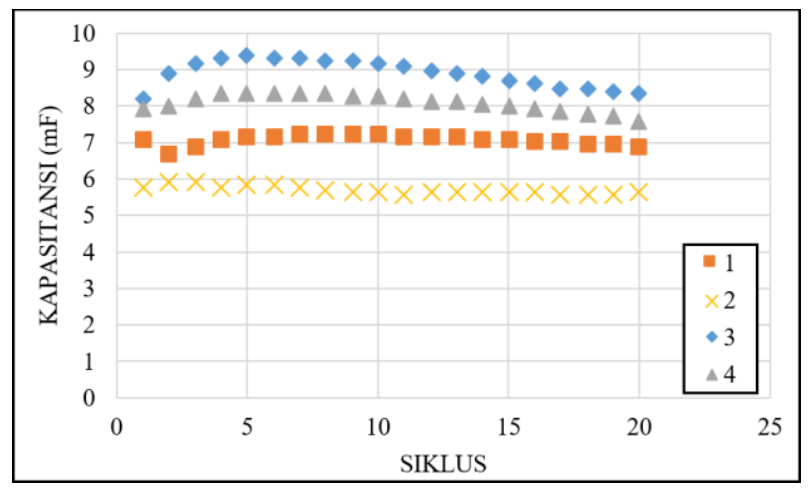

Gambar 6. Grafik stabilitas sistem baterai ditinjau dari nilai kapasitansi terhadap siklus

Berdasarkan data yang ditunjukkan Gambar 6, maka dapat diketahui nilai kapasitansi dari siklus ke-21, 22, 23 dan seterusnya dengan ekstrapolasi data menggunakan pendekatan garis lurus, sehingga dapat diprediksi banyaknya siklus yang dapat dilakukan hingga tercapainya drop capacity (nilai kapasitansi $=0$ ). Ditunjukkan pada Tabel 4.

Tabel 4. Drop capacity pada siklus film anoda

\begin{tabular}{cccc}
\hline \multirow{2}{*}{ Sampel } & \multicolumn{2}{c}{ Film } & \\
\cline { 2 - 3 } & Komposit & d (mm) & Siklus \\
\hline 1 & \multirow{2}{*}{ Grafit/C/CMC } & 0,177 & 245 \\
2 & & 0,369 & 1525 \\
3 & & 0,200 & 100 \\
4 & Grafit/AB/CMC & 0,422 & 140 \\
\hline
\end{tabular}

Berdasarkan Gambar 6 terlihat bahwa sistem baterai dengan anoda komposit Grafit/C/CMC ketebalan 0,369 mm memiliki nilai kapasitansi yang cukup rendah. Namun berdasarkan Tabel 4 terlihat bahwa sampel ini memiliki stabilitas yang paling baik. Dilihat dari banyaknya siklus yang dapat dilakukan yaitu sebanyak 1525 siklus.

\section{Kesimpulan}

Telah dibuat film anoda dengan variasi bahan konduktif dan variasi ketebalan film menggunakan binder CMC. Berdasarkan hasil pengujian, dapat disimpulkan bahwa pemberian bahan konduktif serta binder CMC berpengaruh terhadap kualitas anoda yang ditinjau dari segi konduktivitas, kapasitansi, serta siklus hidup. Film anoda komposit Grafit/AB/CMC ketebalan 0,200 mm memiliki konduktivitas terbesar yaitu $6,781 \times 10^{3} \mathrm{~S} / \mathrm{m}$. Nilai kapasitansi terbesar dimiliki oleh sistem baterai dengan 
film anoda komposit Grafit/AB/CMC ketebalan 0,422 mm yakni sebesar 9,4mF. Namun yang memiliki stabilitas terbaik adalah sistem baterai dengan film anoda komposit Grafit/C/CMC ketebalan 0,369 mm yang memiliki siklus hidup sampai dengan 1525 siklus..

\section{Daftar Pustaka}

1. D. Linden and T. B. Reddy. 2001. Handbook of Batteries 3rd Edition. New York: Mcgraw-Hills Companies, Inc.

2. J. Ni, Y. Huang, L Gao., A high-performance hard carbon for $\mathrm{Li}$-ion batteries and supercapacitors. Journal of Power Sources Vol. 223 (2013) 306 - 311.

3. Cp Kelco. (2009). Cmc Book $1^{\text {st }}$ Edition. United States

4. J. Drofenik, M. Gaberscek, R. Dominko, Cellulose as a Binding Material in Graphitic Anodes for Li ion Batteries: a performance and degradation study. Electrochimica Acta (2002) 883-889. 